Bjarne Blom*

\title{
Terminometry - \\ how termish is a term?
}

\begin{abstract}
Is a term merely a term, or are some terms more termish than others? This is the fundamental underlying theoretical question of the present study of the terminology of the Danish VAT act. ${ }^{1}$ The introduction of the concept "termhood" provides for term differentiation in terms of degree. Termhood allows us to determine whether for example "VAT exempt goods" is more termish than "taxable person" within the context of VAT legislation .
\end{abstract}

THIS FOUR DIMENSIONAL BAR CHART is a terminological and conceptual reflection of the Danish VAT act:

1 This paper presents the results of the Danish team of the EU-backed Greek-ItalianDanish RENOS-project (Reduction of Noise and Silence in Full Text Retrieval Systems for Legal Texts).

* Bjarne Blom

The Aarhus School of Business

Fuglesangs allé 4

8210 Aarhus $V(D K)$

Hermes, Journal of Linguistics no. 13 - 1994 
THE FIRST DIMENSION OF THE CHART represents the "termhood" of the linguistic inventory of the VAT act.

The degree of "termishness" - or rather termhood - has been determined by means of a scale ranging from 9 (the highest score) to 0 (the lowest score). Each individual word occurring in the VAT act has been allocated a termhood value according to the extent to which it may be said to be a term.

THE SECOND DIMENSION shows the conceptual zones of the VAT act.

The act has been analysed with a view to establishing the conceptual pattern of the act. The conceptual universe of the Danish VAT act boils down to three overall categories, namely (i) the taxable subject, i.e. the taxpayer, (ii) the taxable object, i.e. the particular goods or services being taxed, and (iii) the VAT itself.

The VAT act operates with a set of parameters as to define and determine the taxability of the subject and the object, and these may be grouped as sub-categories of each of the three categories.

The parameters relating to the subject are (a) a geographical parameter, which has to do with the place of trade of the subject; (b) a status parameter, i.e. the status of the subject as regards registration for VAT; (c) a generic parameter which deals with the particular type of transaction involved and the particular type of enterprise participating in this transaction, (d) a regulative parameter which has to do with commissive and deontic implications for the subject, i.e. the rights and obligations.

The following set of parameters applies to the object of taxation: (a) a geographical parameter, by which is meant the origin and/or the destination of the goods or services bought or sold; (b) a status parameter to allow for a distinction between goods or services; (c) a generic parameter is used to define the particular nature and use of the taxable object.

The VAT category comprises a number of sub-categories: (a) legislation, i.e. the VAT act itself as well as other acts referred to in the VAT act and public authorities administering and enforcing the act; (b) the nature and technical framework of the tax. 
THE THIRD DIMENSION OF THE CHART shows the conceptual distribution rating of each word. Each individual word has been given a total of sixteen points to distribute among eight conceptual categories. This is to reflect the weight with which words occur within the conceptual categories. If the distribution is maximal, there are two points in each slot, whereas a non-distribution will leave sixteen points in one slot. This will give us an idea of the termhood of the words of the VAT act in relation to the conceptual areas in which they occur.

What is shown on the vertical axis of the chart is the total amount of peaks, i.e. potential terms.

The fact that a particular category has a particular total number of peaks does bring us one step closer to an understanding of their underlying termhood. The mere number of peaks, however, may simply reflect the fact that a certain category contains a lot of members, whereas other categories do not have enough members to sufficiently push the chart bar upwards. However, a cross-tabulation of number of peaks and number of zeros will provide a picture of the termhood involved, and this is what our fourth dimension is about.

THE FOURTH DIMENSION OF THE CHART is found inside the bars. They may be considered as boxes that one can open and look into in order to find the relevant words inside written on paper slips with a certain length according to the number of zeros that are provided by the distribution of the sixteen points. The highest zero-score is seven (in case the sixteen points gather in one slot, seven slots will be empty), the lowest zero-score is zero (in case of non-distribution there are no empty slots).

The chart bar rises according to the number of peaks and number of zeros, and so does the termhood value.

INTERESTINGLY ENOUGH the termhood value intuitively allocated to each word prove to be valid in most cases. Each word has been checked in context, and on the whole the values allocated hold through. Moreover, the bar chart actually reflects the Danish VAT act: the particular domain dealt with, VAT, is reflected by the largest bar by far, the inherent authoritative status of the act is reflected as well, and it is apparent that although the taxable object is of great importance, the taxable subject receives the main focus of attention. After all, it is he or she who has to pay the tax levied on the taxable object. 
